\title{
Segredos da história do Brasil revelados por Gustavo Barroso na revista O Cruzeiro (1948-1960)
}

\section{Secrets of Brazilian history exposed by Gustavo Barroso in the magazine O Cruzeiro (1948-1960) \\ Aline Montenegro Magalhães e Claudia Barroso Roquette-Pinto Bojunga}

Gustavo Barroso tornou-se o mais assíduo dos mestres da História contada ao povo do Brasil. E o Brasil não o esquecerá.

Pedro Calmon, 2 de abril de 1960.

A revista $O$ Cruzeiro de 7 de agosto de 1948 anunciou uma novidade aos seus leitores. Uma nova seção passaria a integrar duas páginas a partir do número seguinte. Dedicada a reportagens sobre o passado, traria o título "Segredos e

\footnotetext{
Aline Montenegro Magalhães é doutora em História, pesquisadora do Museu Histórico Nacional e professora na UNESA (alinemontenegro@gmail.com).

Claudia Barroso Roquette-Pinto Bojunga é graduada em Jornalismo e em História pela PUC-Rio e pesquisadora associada ao projeto Escritas da História no Museu Histórico Nacional (1922-2012) - Produção barroseana difundida na grande imprensa (claudiabojunga@gmail.com).

Este artigo foi recebido em $1^{\circ}$ de julho e aprovado para publicação em 8 de setembro de 2014 .

O trabalho é parte do projeto de pesquisa Escritas da História no Museu Histórico Nacional (1922-2012), inscrito na Faperj desde 2011, cuja etapa "Na imprensa: o caso de Segredos e revelações da História do Brasil" é apoiada pela bolsa de produtividade da Universidade Estácio de Sá desde março de 2014.
} 


\section{Aline Montenegro Magalhães e Claudia Barroso Roquette-Pinto Bojunga}

revelações da História do Brasil" e seria assinada por Gustavo Barroso, membro da Academia Brasileira de Letras (ABL) e diretor do Museu Histórico Nacional (MHN).

A seção "Segredos e revelações da História do Brasil" foi escrita por Gustavo Barroso entre 14 de agosto de 1948 e 23 de março de 1960 (mesmo após sua morte, em 3 de dezembro de 1959, os artigos que havia deixado prontos continuaram a ser publicados). Esse período coincide com a época áurea da revista. O semanário de circulação nacional - que integrava a rede Diários Associados, de Assis Chateaubriand, o Chatô - iniciara uma grande virada com a entrada, em 1943, de Frederico Chateaubriand, sobrinho de Chatô. Foi com Freddy que a publicação passou a estampar reportagens ricamente ilustradas, que por vezes ocupavam páginas inteiras e se tornaram sua marca registrada. $\mathrm{O}$ fotógrafo francês Jean Manzon também foi contratado nessa época, trazendo a experiência que havia acumulado como repórter fotográfico da revista Paris Match e do diário Paris Soir. Essa mudança editorial alavancou as vendas de $O$ Cruzeiro. Segundo Peregrino (1991: 24), se em 1945 a tiragem da revista chegou a 80 mil exemplares, em 1954, com o suicídio de Vargas, sua venda mais que dobrou, alcançando a marca de 720 mil exemplares vendidos - um número recorde que só foi ultrapassado pela revista Veja décadas mais tarde, em um país já de outras proporções.

Sem dúvida desde o seu lançamento, em 1928, o projeto da revista de Assis Chateaubriand foi ambicioso. Em 5 de dezembro daquele ano, dias antes de a primeira edição estar disponível para venda, criou-se uma estratégia de divulgação que despertou a curiosidade de quem passava pelo Centro do Rio de Janeiro. Quatro milhões de folhetos foram lançados do alto de prédios na Cinelândia, na avenida Rio Branco e na rua do Ouvidor - o coração da cidade -, anunciando: "Cruzeiro, a revista contemporânea dos arranha-céus!”. A ideia deu certo: o primeiro número de Cruzeiro (que passaria a incorporar o artigo " $O$ " no título apenas em 1929) esgotou nas bancas.

Com impressão em quatro cores, destaque para ilustrações e circulação em todas as capitais e em algumas das principais cidades do país, O Cruzeiro inovou desde o começo. Ao alcançar localidades muito além do eixo Rio-São Paulo, tornou-se um veículo da integração nacional. $\mathrm{O}$ nacionalismo e a preocupação com o novo, com a modernidade, norteavam o conteúdo das edições. O primeiro editorial já anunciava essas características:

Depomos nas mãos do leitor a mais moderna revista brasileira. Nossas irmãs mais velhas nasceram por entre as demolições do Rio colonial, através de cujos escombros a civilização traçou a reta da Avenida Rio Branco: uma reta entre o passado e o futuro. Cruzeiro en- 
contra já, ao nascer, o arranha-céu, a radiotelefonia e o correio aéreo: o esboço de um mundo novo no Novo Mundo. [...] Porque é a mais nova, Cruzeiro é a mais moderna das revistas. É este o título que, entre todos, se empenhará por merecer e conservar: ser sempre a mais moderna num país que cada dia se renova, em que o dia de ontem já mal conhece o dia de amanhã; ser o espelho em que se refletirá, em períodos semanais, a civilização ascensional do Brasil, em todas as suas manifestações; ser o comentário múltiplo, instantâneo e fiel dessa viagem de uma nação para o seu grandioso porvir; ser o documento registrador, o vasto anúncio ilustrado, o filme de cada sete dias de um povo, eis o programa de Cruzeiro.

Ao se autointitular moderna como o Brasil, a revista imprimia em suas páginas a ideia de sintonia com um país em constante renovação, que ingressava no rol das nações civilizadas, e fazia com que seus leitores se identificassem com esse Brasil moderno e com o próprio periódico, que traduzia essa civilização e modernidade em suas matérias. $\mathrm{O}$ nome da revista reforçava essa relação, já que Cruzeiro representaria tanto a constelação do Cruzeiro do Sul como as estrelas presentes na bandeira brasileira - símbolo do Estado, cuja valorização pode ser associada ao nacionalismo. O nome denotaria também a nova moeda que começava a circular no Brasil e seria uma referência à inspiração para os primeiros nomes destas terras quando da chegada dos portugueses. Assim, segundo Barbosa (2000: 6), Cruzeiro "é, ao mesmo tempo, símbolo cristão e símbolo-síntese da nacionalidade". Além disso, a revista parecia ter a intenção de ser, como a constelação, um guia para os brasileiros rumo ao progresso.

Com o passar do tempo, a valorização do Brasil foi se concretizando nas páginas de $O$ Cruzeiro, ganhando bastante força com a fotorreportagem, que, segundo Marlise Regina Meyrer (2012: 2), "impôs-se como um novo modelo de jornalismo em consonância com um tempo em que a sociedade urbana se estabelecia como modo de vida hegemônico". Nas décadas de 1940 e 1950 - período em que Gustavo Barroso escreveu na seção "Segredos...”-O Cruzeiro agregou às suas páginas reportagens sobre um Brasil desconhecido, em que os indígenas eram apresentados como símbolo da nacionalidade. Tanto os recônditos brasileiros como os índios eram apresentados do ponto de vista exótico. De acordo com a autora: "A construção da identidade nacional é um dos elementos básicos de acesso à civilização conforme este conceito é entendido e utilizado pela revista $O$ Cruzeiro, que entendia que este processo passava também pela organização, hierarquização e integração do espaço físico do país" (Meyrer, 2012: 2).

Gustavo Barroso afinava-se com o projeto editorial da revista ao apresentar uma história pátria que carregava nas tintas da exaltação nacional e procu- 
rava constantemente inserir o Brasil no rol das nações civilizadas. Mas se $\mathrm{O} C r u$ zeiro recorria às paisagens naturais brasileiras e ao exótico, investindo também na ideia de um futuro que já se tornava presente, Barroso buscava trazer à tona um passado civilizado para o Brasil. Suas curiosidades históricas não deveriam apenas atrair a atenção do público, mas cultivar o orgulho patriótico com base no estabelecimento de um vínculo entre o Brasil e os referenciais do mundo civilizado, ou seja, a Europa. Essa aproximação estava muito presente na filiação do Brasil a Portugal, especialmente na continuidade monárquica e católica do Estado - vide o artigo "Um Rei de Portugal, Imperador do Brasil" (Barroso, 09/09/1950: 36). Ela também aparecia nas relações pessoais entre brasileiros e europeus ilustres, como na amizade entre D. Pedro II e Gobineau (Barroso, 28/05/1949). Apresentava-se ainda na inserção do Brasil numa temporalidade mais recuada, o que atribuía à história nacional uma antiguidade - em termos de civilização - ainda maior do que se poderia imaginar, conforme o artigo "Os fenícios no Brasil": nele, cotejando documentos sobre pesquisas arqueológicas realizadas no século XIX em torno de inscrições na Pedra da Gávea, no Rio de Janeiro, Barroso voltava a levantar a questão de se tratar ou não de provas da presença de fenícios, na região depois denominada Bahia de Guanabara, no longínquo século VII a. C. (Barroso, 19/11/1949).

Na década de 1950, além de ser distribuída por todo o Brasil, a revista $O$ Cruzeiro ganhou uma edição internacional que circulava por países da América Latina e do Caribe e no sul dos Estados Unidos. O leitor que comprava um exemplar se deparava com grandes fotorreportagens, com seções que ficaram célebres, como as humorísticas Pif-Paf, de Millôr Fernandes, e Amigo da Onça, assinada por Péricles, e ainda com textos saídos da pena de intelectuais como Rachel de Queiroz, Gilberto Freyre e José Lins do Rego.

Gustavo Barroso somava-se ao qualificado quadro de colaboradores da revista para enriquecer seu programa de patriotismo. Tratava de informações que deveriam despertar a curiosidade dos leitores e prendê-los semanalmente às bancas em busca de novos conhecimentos sobre fatos pretéritos. Entretanto, os objetivos de sua seção, segundo o texto que a anunciava em agosto de 1948, iam além do entretenimento, que, na verdade, era visto como um meio para que os "amigos da revista" passassem a se interessar e a se emocionar com as "fortes e contínuas sugestões de amor por nossa pátria" (O Cruzeiro, 07/08/1948: 10). Conforme proposta explicitada na apresentação, havia um objetivo pedagógico claro na edição da coluna:

A História do Brasil é rica em episódios e fatos curiosos, interessantes e heróicos que a tornam às vezes um poema e outras, uma 
verdadeira epopeia. Também está cheia de fascinantes segredos, cuja revelação explica atitudes humanas de súbito valor ou aspectos político-sociais da mais alta significação. Infelizmente nos livros eruditos [...] nos compêndios didáticos, nem sempre esses assuntos são apresentados de forma que desperte a atenção dos leitores. Afogam-nos os documentos com sua linguagem antiquada [...] as longas citações e [...] acumulação de datas. Tudo isso faz com que a nossa história não nos ofereça uma leitura amena e convidativa. Os estudiosos encontram nela muito o que aprender, mas o público em geral a ignora nos seus aspectos mais agradáveis, humanos e sensíveis. [...] Nenhum povo pode amar suas tradições, seus grandes homens e as obras que por ele realizaram-se neste mundo se as não conhece, se não sabe os porquês de sua origem, de sua formação e do seu sentido na vida. [...] Foi pois depois de meditar sobre essas considerações que a direção de $O$ Cruzeiro resolveu publicar do seu próximo número em diante algumas páginas sobre coisas pouco conhecidas da História do Brasil (Idem).

Apostando na combinação de textos fluidos, temas curiosos e imagens, O Cruzeiro pretendia ensinar história aos leitores e cultivar neles o amor ao passado, às tradições, à pátria. Na medida em que a revista criticava os espaços consolidados de divulgação da história, tidos como enfadonhos, e buscava atingir um público amplo e diversificado, podemos compreender e analisar a seção "Segredos..." como lugar de prática de uma história pública, uma vez que se tratou de uma experiência de "apresentação popular do passado para um leque de audiências" (Liddington, 2011: 34), tendo a grande imprensa como veículo.

\section{Sobre o autor}

Gustavo Barroso já produzia história em outros meios de publicação, entre eles livros especializados, como a História militar do Brasil (1935), e revistas acadêmicas, como a do Instituto Histórico e Geográfico Brasileiro (IHGB) e os Anais do Museu Histórico Nacional. Quando começou a escrever para O Cruzeiro, já contava 60 anos de idade e era um intelectual reconhecido, o que é possível perceber a partir das credenciais que acompanhavam sua assinatura na seção "Segredos ...": membro da Academia Brasileira de Letras e diretor do Museu Histórico Nacional. A integração à ABL, onde ingressou com apenas 34 anos, garantia sua credibilidade intelectual. Já a direção do MHN lhe conferia autoridade no tema ao qual iria se dedicar naquele espaço: a História do Brasil. Gusta- 
vo Barroso não era apenas o diretor do museu; foi também um de seus idealizadores e fundadores, em agosto de 1922, ano do Centenário da Independência do Brasil. Vincular seu nome a essas instituições de produção e circulação do saber, especialmente historiográfico (De Certeau, 2000: 66-67), garantiria legitimidade para a sua escrita. Barroso poderia ter incluído nos seus créditos "membro do IHGB", instituição à qual se vinculava desde 1932, voltada para a investigação e escrita da história nacional desde 1838, mas parece ter dado preferência à instituição que dirigia, o $\mathrm{MHN}$, como vinculação institucional relacionada à produção historiográfica, por ter sido o lugar onde teve maior atuação.

Gustavo Barroso foi diretor do MHN até o ano de sua morte, em 1959, tendo ficado afastado por apenas dois anos por razões políticas. ${ }^{2}$ Sua relação com a História vinha não apenas da concepção do museu e da grande quantidade de livros que escreveu sobre o tema-como, entre outros A Guerra do Lopez (1928), A Guerra do Rosas (1929), História do Palácio do Itamaraty (1956) -, mas também da disciplina que ministrava no Curso de Museus, criado em 1932 no MHN: História Militar do Brasil. Os textos em O Cruzeiro não foram sua primeira incursão na imprensa. Quando tinha 18 anos, publicou seu primeiro texto - um artigo sobre o Descobrimento da América - em A República. Em 1916, já bacharel em Direito, tornou-se diretor da revista Fon-Fon no Rio de Janeiro, tendo também colaborado em revistas como O Malho e Tico-Tico, além de jornais como o fornal do Brasil, fornal do Commercio e muitos outros.

Apesar de ter tido um vida política muito ativa, no momento em que passou a escrever “Segredos...”, Gustavo Barroso já não tinha mais atuação nesse campo. Fora deputado federal pelo Ceará (1914-1918) e tivera uma participação ativa no movimento integralista, aderindo em 1933 à Ação Integralista Brasileira (AIB), criada por Plínio Salgado no ano anterior. Além de publicar textos em que desenvolvia teses integralistas e antissemitas, chegou a disputar a candidatura à presidência da República pela AIB, para o pleito de 1938, com Salgado e Miguel Reale. Com a implantação do Estado Novo em 1937, porém, as eleições foram suspensas e os partidos políticos acabaram sendo extintos.

Prolífico escritor, Gustavo Barroso publicou um total de 128 livros, entre eles livros de história, estudos sobre folclore, romances, contos, ensaios etc. Quando passou a assinar "Segredos...", dedicou-se a outro tipo de divulgação do conhecimento histórico, uma espécie de transposição da produção acadêmica para um veículo acessível ao grande público, o que já havia feito de forma menos sistemática na Fon-fon quando a dirigiu. Não assinava então uma coluna específica, mas era frequente ver artigos de sua pena com temática histórica. Um exemplo é o texto "O amor e a política", publicado na Fon-fon de 11 de abril de 1925 e depois também n'O Cruzeiro de 13 de novembro de 1948. Ainda segundo o texto de apresentação da nova seção de $O$ Cruzeiro, os segredos da história do Brasil se- 
riam revelados aos leitores nas páginas da revista "desde os [ilegível] do Descobrimento, numa seriação cronológica, até os da República [...]" (O Cruzeiro, 07/08/1948). A série se iniciou com as primeiras missas no Brasil, vistas como o “amanhecer da civilização cristã em terras de Santa Cruz" (Barroso, 14/08/1948: 20), mas acabou por não se prender à cronologia e passou a abordar os fatos da história fora de uma linearidade temporal.

Ricamente ilustradas, as páginas de "Segredos..." se valiam de documentos escritos, cartográficos, iconográficos e materiais para demonstrar aos leitores a verdade das revelações feitas. Entre as fontes utilizadas, constavam muitos itens do acervo do MHN. Aliás, Barroso transpunha para as páginas de $O$ Cruzeiro a história produzida no $\mathrm{MHN}$, exposta nas galerias e publicada em seu principal órgão de divulgação, os Anais. Uma história fortemente marcada pelo caráter político, de valorização do Estado, especialmente o monárquico, da ação civilizadora da Igreja Católica nos trópicos e dos grandes feitos militares, já tão criticados, mas ainda com forte presença em instituições de ensino e pesquisa (Ferreira, 2013: 39). Aproximava-se assim da tradição historiográfica fundada no IHGB por Francisco Adolfo de Varnhagen, por ele considerado um "grande historiador brasileiro", especialmente pela aposta que fez de construir a identidade nacional e estimular o amor à pátria a partir da vinculação do Brasil às raízes lusitanas. Nessa perspectiva, os índios eram abordados de três modos: como selvagens "inimigos", quando obstáculo para a colonização; como heróis, nos casos em que se renderam à civilização europeia, pela conversão ao catolicismo e pela colaboração com a empresa colonial; ${ }^{3}$ e como exóticos, quando foram estranhados pelos europeus, e suas práticas culturais serviram de curiosidade e divertimento para esse "outro".

No primeiro caso, temos o exemplo do texto "Guerras de corso e de morte”, no qual Barroso relata as guerras de extermínio e escravização dos índios no Nordeste:

Embora a colonização portuguesa no Brasil sempre se tenha desenvolvido com pacífica intenção, muitas vezes, apesar das recomendações régias e dos cuidados dos catequistas, houve lutas bravas contra o silvícola, do que proveio o desaparecimento de tribos inteiras. [...] devido ao fato de os indígenas caçarem e destruírem os rebanhos. [...] Assim, além das guerras parciais, gerais ou livres que se faziam contra os indígenas rebeldes, inadaptáveis, mal afamados, ladrões de gado ou matadores de gente e das lutas entre os poderosos clãs de colonizadores que os tomavam como acostados, capangas ou cangaceiros, ainda o gentio era usado, quando já mais ou menos reduzido à civilização, como 


\section{Aline Montenegro Magalhães e Claudia Barroso Roquette-Pinto Bojunga}

tropa auxiliar nas milícias brancas ou mestiças contra seus irmãos de sangue (Barroso, 18/12/1948: 29; 34).

Segundo essa visão, a empresa colonizadora, com seus propósitos pacíficos, se via obrigada a recorrer às armas e a subjugar os nativos à escravidão pelo fato de estes serem obstáculos ao seu empreendimento. Assim, como uma espécie de legítima defesa, ficava ela isenta de qualquer responsabilidade pelo que ocorreu com os índios; ao contrário, suas ações eram justificadas em nome de um projeto civilizador.

Nos casos em que a resistência deu lugar à colaboração após os índios abraçarem o cristianismo, a iniciativa foi louvada. Foi o que aconteceu com Martim Afonso Tibiriçá, chefe dos indígenas guaianases, que contribuiu para a fundação da cidade de São Paulo. A ele Barroso dedicou um artigo tendo como mote seu tacape, acervo do MHN.

Entre os chefes indígenas que no amanhecer do Brasil, ao se iniciar nossa colonização, fizeram causa comum com os portugueses, o mais ilustre foi, sem dúvida, aquele à sombra de cuja fiel amizade devemos o estabelecimento de Piratininga, berço da metrópole paulistana de nossos dias. [...] Graças à proteção de Tibiriçá, ao calor de seu prestígio pessoal no meio da indiada, produziram-se as primeiras mestiçagens [...] Esse chefe dos guaianases de Piratininga deixara-se converter à fé cristã pelos padres José de Anchieta e Leonardo Nunes. Graças a Tibiriçá, puderam os padres da Companhia de Jesus permanecer no planalto piratiningano e fundar ali seu primeiro povoado missioneiro [...] o morubixaba Tibiriçá foi, na verdade, o laço que uniu no mesmo instintivo desejo de progresso, no mesmo informe anseio de futuro o índio bravio e o aventureiro civilizado, sob os braços acolhedores, pacificadores e luminosos da Cruz (Barroso, 04?/08/1951).

Neste caso, tem-se a glorificação de uma trajetória que justificava a presença de um objeto no acervo do MHN: o tacape atribuído ao indígena, considerado por Barroso uma "relíquia preciosíssima", cuja autenticidade era atestada por ter pertencido a d. Pedro II, que o teria doado a Couto de Magalhães (Bezerra, 2010: 155-175). Não por acaso, a reportagem de "Segredos..." estampa uma imagem de página inteira do Imperador, agregando mais valor ao artefato e à sua história, mesmo levantando-se a dúvida do real pertencimento a Tibiriçá.

Por fim, também houve a abordagem dos índios como seres exóticos. Foi com esse olhar que Barroso relatou a presença deles na corte francesa. Ao es- 
crever o artigo "Os Tupinambás dançam na França”, o escritor teve por intenção "revelar" uma aproximação inusitada e pouco conhecida do Brasil com a Europa, da barbárie com a civilização.

Pouquíssimos brasileiros sabem que, em 1550, meio século após o Descobrimento do nosso país, 50 Tupinambás escolhidos dançaram e fizeram combates simulados para divertir a civilizada Corte de França, em presença da famosa Rainha Catarina de Médicis, à margem do Sena.

Pois é verdade. [...] Nesse século XVI, tão célebre em toda a Europa pela pompa de suas cavalgadas, entradas solenes, préstitos deslumbrantes e torneios magníficos, não faltou numa das Cortes mais elegantes do continente europeu o exotismo fascinante dos selvagens brasileiros (Barroso, 11/09/1948: 70 - grifos nossos).

Quanto aos negros, o mesmo tratamento: quando subverteram a ordem escravocrata e conquistaram a ascensão social pela arte, pelas letras ou pela política, a valorização. Nos outros casos, a romantização, a folclorização ou o silêncio (Magalhães, 2006: 27-43). Caetano Lopes de Moura, um "homem de cor", por exemplo, foi louvado no artigo "Um baiano na retirada da Rússia". Além de ter-se formado em medicina em Coimbra e ter recebido o título de doutor da Faculdade de Paris, o personagem ingressou no corpo de saúde do Exército da Legião Portuguesa, tendo participado de guerras pelo Exército francês, "assistindo a glórias sem par". Escreveu livros, traduziu outros, tendo recebido, ao final de sua vida, uma pensão de d. Pedro II, "o magnânimo" (Barroso, 28/05/1949). Mais uma vez o elo entre Brasil e Europa era estabelecido, nesse caso pela atuação de um negro letrado, doutor e ainda por cima militar, carreira tão cara a Barroso.

Outro artigo que aborda os negros tem por objetivo amenizar a violência da escravidão na história do Brasil. Gustavo Barroso começa o texto "Os ferros da escravidão" afirmando que a escravidão estava mais para purgatório do que para inferno. $\mathrm{O}$ autor não nega que a tortura foi uma prática, mas defende que a crueldade com os escravos foi menor do que se costuma pensar. Para comprovar a argumentação, afirma que a taxa de mortandade nos navios negreiros era de apenas $5 \%$, enquanto a de navios que transportavam passageiros livres era de $10 \%$.

Barroso descreve instrumentos de castigo como a palmatória e a peia cujas fotos, inclusive, ilustram o texto - explicando o uso de cada um deles. No caso das mordaças de ferro, explica, sua função não era a tortura, e sim impedir que os escravos com anquilostomíase duodenal comessem terra (um dos sinto- 


\section{Aline Montenegro Magalhães e Claudia Barroso Roquette-Pinto Bojunga}

mas da doença). Assim, demonstra como tais instrumentos eram usados por vezes de forma "positiva" pelos senhores de escravos. Comenta ainda como a lei, com o tempo, passou a "proteger" os escravos: "Desde o século XVII, o Governo Real se preocupava em evitar que os escravos fossem torturados fisicamente e cruelmente castigados" (Barroso, 30/04/1949). Sua afirmação baseava-se na carta régia de 1688, datada de 20 de março, que proibia os castigos aos senhores e os obrigava a punir com moderação e de acordo com a lei.

\section{Revelando os segredos}

Os artigos de "Segredos e revelações da História do Brasil" aqui analisados constituem seis volumes encadernados que integram a Hemeroteca Gustavo Barroso da Biblioteca do MHN, composta de 100 volumes, entre cadernos e maços de recortes de jornais. Uma parte foi organizada por ele mesmo, outra por empresas especializadas em clipping, e outra ainda pela museóloga Nair de Morais Carvalho, seu braço direito no MHN (Magalhães, 2012: 60-68). Nos seis volumes em que constam os fascículos d' O Cruzeiro, há apenas as páginas das matérias assinadas por Barroso, ordenadas pela data de publicação. Não há capas das revistas. É provável que Barroso tenha começado as encadernações e d. Nair, como é conhecida, as tenha concluído, pois os volumes estão completos e, como se sabe, seus artigos foram publicados postumamente até março de 1960 . O primeiro volume vai até o artigo publicado em 31 de dezembro de 1949. Os demais abrangem dois anos de publicação da série cada um.

Barroso preparou essa coleção para Plínio Doyle, para quem fez uma dedicatória na folha de rosto do primeiro volume da encadernação: "Ao muito querido amigo Plínio Doyle, um afetuoso abraço, Gustavo Barroso. Rio, 11.6.59". Entretanto, não teve oportunidade de oferecê-la ao amigo que gostava tanto de colecionar livros, papéis e fascículos de revistas (Lustosa, 2012: 26-36).

A primeira página da seção é sempre inteiramente dedicada ao tema a ser tratado, geralmente aparecendo entre as páginas 20 e 30 da revista. O nome da seção é apresentado na parte superior à esquerda, seguido imediatamente abaixo de um título chamativo em tamanho bem maior. Logo abaixo vem o subtítulo que esmiúça o assunto, e depois a assinatura do autor com suas credenciais. A primeira parte do texto é acompanhada de imagens e sempre procura elucidar a novidade que o leitor conhecerá ao longo da matéria, com uma pequena introdução que parte de algo que, presume-se, já é de seu conhecimento. As demais partes do texto seguem em outras páginas, dividindo espaço com matérias iniciadas em outros espaços da revista, publicidade e, às vezes, mais imagens relativas ao tema. É perceptível uma crescente mudança no layout da seção a partir do núme- 
ro de 5 de maio de 1954. A matéria passa a ocupar um espaço menor na revista. Dependendo do artigo, o número de imagens é menor ou a quantidade de texto diminui, muitas vezes ocupando apenas uma ou duas páginas. Em janeiro de 1955 é perceptível mais uma diminuição no número de imagens e, muitas vezes, no seu tamanho. Entretanto, a mudança mais radical na seção acontece a partir de 17 de maio de 1958, quando passa a vir estampado um retrato de Gustavo Barroso, encimado pela palavra "HISTÓRIA", que em 11 de julho de 1959 já desaparece. Com a nova diagramação, a seção passa a não contar mais com imagens, e o texto passa a ocupar apenas uma página.

A seção foi inaugurada com um tema do período colonial intitulado "A primeira imagem e a primeira cruz do Brasil". Tinha por objetivo "revelar" que a imagem pintada por Victor Meirelles não era a da primeira missa realizada no Brasil:

A cena histórica do nosso país mais vulgarizada no seio de todas as camadas da população é certamente a denominada "Primeira missa do Brasil". Pintou-a em vasta tela, que se acha no Museu de Belas Artes, o grande artista catarinense Vítor Meireles. Suas reproduções [...] correm por aí afora nos livros ilustrados, nos compêndios didáticos, nas folhinhas do ano, no reverso das cédulas, nos jornais e nas revistas. Até mesmo pelo estrangeiro vai sendo repetida a magnífica pintura do amanhecer da civilização cristã em terras da Santa Cruz [...] O quadro de Vítor Meireles [...] também se poderia chamar - O Anúncio da Civilização cristã, em cujas formas ideais e rumos se plasmaram os destinos do Brasil. [...] pouquíssimos sabem que a cena por ele pintada é de fato, "a segunda missa" dita na nossa terra. Esta é a interessante revelação que nos faz o mais autêntico documento histórico, a Carta escrita por Pero Vaz de Caminha ao Rei de Portugal, descrevendo o achado do Brasil [...] verdadeira reportagem do grande acontecimento. Vejamos, pois, o que diz a história. (Barroso, 14/08/ 1948: 21 - grifos nossos).

Barroso partiu de uma imagem bastante conhecida dos leitores para desconstruir a ideia consagrada de que esta se referia à primeira missa no Brasil. Para fundamentar seus argumentos, recorreu à prática da comprovação com base em documento "autêntico", a Carta de Pero Vaz de Caminha. E, reproduzindo trechos da narrativa documental, comentou sobre as duas missas que tiveram lugar no Brasil. É interessante notar que quem faz a "interessante revelação" não é Barroso, mas sim Caminha em sua carta, num claro posicionamento de imparcialidade diante dos fatos pela autenticidade das fontes que, nessa concepção 
de ciência histórica, "falam por si". A partir daí, o leitor tem a oportunidade de acompanhar o exercício de desconstrução de uma ideia e construção de outra, a da real primeira missa realizada, da qual não se tem uma pintura, mas um objeto que a ela remete, nas coleções do $\mathrm{MHN}$ : a réplica da cruz que teria sido usada por Frei Henrique de Coimbra, conforme relata:

Essa cruz de nossa Primeira Missa, que viajou de Lisboa ao Brasil e à Índia na armada de Cabral, que acompanhou Frei Henrique de Coimbra à diocese de Ceuta, que veio para Olinda em 1584 e retornou a Portugal após a invasão holandesa se encontra milagrosamente conservada no Museu Arquiepiscopal na cidade de Braga. Durante as comemorações centenárias de Portugal, em 1940, o ilustre historiador e meu amigo Augusto de Lima Júnior teve a feliz ideia de obter do eminente Antístite daquela velha e gloriosa diocese portuguesa a permissão de fazê-la copiar, nas mesmas proporções, em ferro do Brasil. Essa reprodução fidelíssima, custodiada hoje em dia no Museu Histórico Nacional, lembra aos seus visitantes a primeira página do cristianismo nas plagas da América do Sul (Idem).

Outro exemplo do uso de imagens recorrentes para trazer à baila revelações está no artigo "A criação da Amazônia", publicado no número de 18 de setembro de 1948. Nesse caso, partiu-se da gravação impressa em papel-moeda do meio circulante para desnaturalizar a constituição do território nacional, lançando luz sobre os grandes feitos de um bandeirante, Pedro Teixeira:

Olhando-se o mapa da América do Sul, observa-se que o nosso continente, ligado ao setentrional por um istmo, afeta a forma dum presunto, com a parte do osso, a mais fina, voltada para baixo. Mais ou menos a mesma configuração apresenta o nosso Brasil contido dentro dele. Desta sorte, parece que, talvez devido somente a essa geometria, deve o território nacional aquela vastidão na região amazônica, em oposição ao estreitamento sulino nas fronteiras do Paraná, Mato Grosso, Santa Catarina e Rio Grande do Sul. Contudo, ao estudarmos os fatos da história do Brasil, verifica-se que isso foi o grandioso resultado da imperecível obra dum grande homem, hoje muito esquecido, infelizmente, por quase todos os brasileiros. Foi ele o grande soldado, o grande desbravador da Amazônia, o grande Bandeirante do Setentrião, Pedro Teixeira. [...] Foi esse homem, hoje quase esquecido, que deu ao Brasil no extremo norte sua vasta extensão territorial. Nas nossas atuais cédulas de 5 cruzeiros, vê-se no re- 
verso, uma cena do século XVII: [...] um grupo central, um cavalheiro estende o braço como a indicar aos que o cercam a direção de onde viera. Embaixo, esta simples legenda: Amazônia. Andam essas notas de cinco cruzeiros de mão em mão [...] mas quantos sabem que o pequeno quadro reproduz a chegada a Quito da expedição de Pedro Teixeira, que deu a Amazônia ao Brasil? (Barroso, 18/09/1948: 58 - grifos nossos).

No trecho citado, é perceptível também a valorização de um personagem histórico, como forma de exaltar as virtudes individuais como marcas indeléveis da formação de um "povo". Marcas que, quando sublinhadas, contribuiriam para o cultivo do amor ao passado comum e, assim, a união dos cidadãos em torno de uma identidade nacional. Essa exaltação aparece repetidas vezes na narrativa de fatos militares, de condutas políticas e da ação evangelizadora da Igreja Católica nos trópicos, numa clara difusão da história como Mestra da Vida (Koselleck, 2006: 42), segundo a qual os leitores deveriam orgulhar-se das suas raízes positivas e aprender com os exemplos do seu passado. Foi nessa direção que Barroso falou sobre Tomé de Sousa quando atribuiu ao seu Regimento o status de Primeira Constituição do Brasil:

Como era o Brasil no seu amanhecer para a civilização. Para dar a medida da honestidade administrativa do homem encarregado de pô-lo em execução, Tomé de Sousa, basta dizer que, durante seu governo, embora fosse o Brasil uma região quase despovoada, não quis tomar para si um pedaço de terra e, somente depois de deixar o cargo, requereu ao Rei, que lhas deu por alvará, seis léguas de chão ao norte da cidade que fundara para recolher o gado vacum, adquirido com as suas economias, que vagava por terras alheias. Esses exemplos bem poderiam ter frutificado na história das nossas administrações. [...] O historiador Varnhagen tinha razão de elogiar como o fez, essa primeira constituição do Brasil (Barroso, 25/09/1948: 34 - grifo nosso).

Da mesma maneira que vai buscar uma ancestralidade maior para a Carta Magna do país identificando a mais antiga Constituição no século XVI, menos de 50 anos depois da chegada de Cabral, com sua associação ao Regimento de Tomé de Sousa, que teria assumido o papel de Constituição em pleno período colonial, Barroso tenta construir uma antiguidade maior para outros fatos da história do Brasil. É assim quando discute a antiguidade do nome Brasil, que seria mais antigo que o próprio Brasil. Segundo afirma, com o auxílio de documentação cartográfica do século XIV e de acordo com "a opinião do 


\section{Aline Montenegro Magalhães e Claudia Barroso Roquette-Pinto Bojunga}

historiador Robert Southey, tão bem informado sobre as coisas de nossa terra, o nome Brasil pegou mais facilmente por já terem os geógrafos antes o posto em voga. [...] resultado duma antiquíssima lenda sobre a existência de uma terra afortunada, abençoada e feliz do lado ocidente, lenda que se misturara como muitas outras, a geografia dos antigos" (Barroso, 28/08/1948). E assim, Barroso vai discorrendo sobre como essa lenda foi apropriada pelos hindus, egípcios, gregos, romanos, na Idade Média etc. Explicando que "Hy Bresail, O’Brasil" derivava da raiz Bress, que significava boa sorte, prosperidade, felicidade, afirmava que um dos primeiros documentos escritos sobre o descobrimento do Brasil comprovava a existência cartográfica anterior desse nome.

Então, ao final do artigo, Barroso lança a seguinte questão para os leitores: "Que preferem os Brasileiros: que o nome de sua pátria signifique Terra Abençoada, Terra Afortunada, Terra dos Bem-aventurados ou recorde unicamente o vulgar e utilitário comércio dum pau de tinta?" (Idem).

Com essa pergunta, Barroso deixava o poder de escolha para seus leitores. Queriam eles o nome de seu país ligado a um passado mais positivo, mais recuado no tempo e filiado às mais evoluídas civilizações da história? Ou se contentariam com a já contada e recontada versão da comercialização do pau de brasa da história mais recente e mais localizada nos trópicos? Recuando seus segredos e revelações no tempo e no espaço, Gustavo Barroso inseria a história do Brasil na história do mundo, ampliando seu espaço de experiências vividas (Koselleck, 2006: 51), e contribuía para a invenção de tradições (Hobsbawm e Ranger, 1997) que deveriam ligar a história nacional às raízes civilizatórias da Antiguidade clássica. ${ }^{4}$

Vários exemplos como este podem ser encontrados nas páginas d'O Cruzeiro, quando não em comprovações "autênticas", como a documentação cartográfica utilizada neste estudo, em analogias de experiências que ocorreram aqui da mesma forma que em outras partes, em outros tempos. É o que ocorre quando a disputa entre portugueses e espanhóis pela Colônia de Sacramento é considerada "a nossa guerra de cem anos", já que "a luta para a sua definitiva fixação durou de 1689 a 1777, isto é, 97 anos, quase um século" (Barroso, 02/04/1949). De acordo com o autor, que vai contando as etapas da disputa em ordem cronológica, aquele foi "o maior choque entre espanhóis e portugueses na América do Sul" (Idem).

Com base nos exemplos aqui tratados, podemos inferir que os temas abordados na coluna não diferiam daqueles presentes nos programas de ensino de História e nos livros didáticos: Descobrimento do Brasil, Presença holandesa no Nordeste, Inconfidência Mineira, Independência do Brasil etc. Destacava-se culto aos estadistas do Império, como d. Pedro II, "o "Magnânimo Imperador do Brasil" (Barroso, 04/06/1949: 56) e d. João VI, considerado o "criador da nação brasileira e o precursor da abolição dos escravos", conforme artigo de 11/09/ 
1954, em que Barroso transcreve o Alvará transitório de 1813, o Tratado de Repressão ao Tráfico de 1815, a Convenção Adicional de 1817 e o Alvará de 1818 para comprovar sua tese:

É justiça assinalar que mais de meio século antes de o poeta [Castro Alves] se indignar com essa monstruosidade [escravidão], um estadista tentara proteger com uma Lei humana os míseros escravos. E fora ele o criador da Nação brasileira D. João VI, então ainda Príncipe Regente. Vejamos o documento comprobatório do que afirmamos. [...] Eis aí o que há mais de um século praticou o Rei D. João VI a favor dos pobres negros trazidos da África para o Brasil: determinou fossem tratados com humanidade a bordo dos navios negreiros, aboliu parcialmente o tráfico e deu liberdade aos escravos negociados ilicitamente. [...] Os documentos que citamos nos autorizam a considerar d. João VI o precursor do abolicionismo em nossa Pátria. É um ato de justiça que se deve à memória do fundador da nação brasileira [...] (Barroso, 11/09/1954: 98).

Os eventos militares também terão espaço na seção. Barroso faz questão de ressaltar os feitos brasileiros, sempre com uma conotação positiva que valorizava a união das "raças" contra um inimigo comum, desde o período colonial até as campanhas do período imperial, com ênfase nas guerras do Prata e especialmente no conflito contra o Paraguai. Sobre a derrota imposta aos holandeses, Barroso escreveu que se tratava da "união dos sangues sob um mesmo pensamento. O espírito nativista. Deus e a Liberdade". Sendo que a grande revelação que fazia aos leitores era a da "superioridade das armas de fogo portuguesas contra os holandeses no Brasil [...] nossos avós portugueses andavam muito mais adiantados do que outros povos em matéria de armamento militar, como em muitas outras coisas" (Barroso, 02/10/1948: 31). Mais interessante é como Barroso ia além das pesquisas históricas tradicionais, que valorizavam mais a documentação escrita, sustentando seus argumentos com base num detalhado estudo de cultura material. A coleção de armaria do MHN é tomada como documento nessa operação (De Certeau, 2000) que é assim demonstrada aos leitores:

\section{Por que tal superioridade?}

A explicação é simples. Os mosquetes e arcabuzes usados naquela época eram chamados de serpentina ou de mecha. A arma tinha na culatra uma caçoleta aberta, onde se punha a escorva, e esta se dava fogo por um pavio, mecha ou serpentina, preso ao chão que o gati- 
lho acionava. Desta sorte, quando chovia antes ou durante o combate, a água molhava a pólvora das escorvas e apagava a chama das serpentinas, ficando a tropa sem poder atirar.

Ora, para [ilegível] inconveniente, um relojoeiro alemão de Nurenbergia, cujo nome a história não guardou, inventou em 1517 o sistema denominado fechos de roda, em que a faísca que detona a arma é produzida interiormente por uma roda a que se dá corda e que, girando, fricciona um sílex ou pirete. Assim, a chuva ou o vento forte não tinham mais atuação sobre as mechas e o fogo se tornava mais seguro na luta.

Esse invento custou a ser introduzido nos exércitos europeus. Levaram alguns deles um século para substituírem seu velho armamento. Pois bem, sendo a invenção de 1517, já em 1549 d. João III encomendava 3 mil arcabuzes desse sistema aos armeiros da Boêmia, os mais ramosos [sic] da Europa. Desde o tempo de d. Manuel, Portugal procurava ter armas de melhor qualidade que os outros povos. Enquanto os orientais e muitos ocidentais estavam ainda no período das colubrinas de mão, dos petrinais e das colubrinas com a mecha de acender a ponta duma vareta, os portugueses possuíam os de mecha-no-chão, com que o Albuquerque e Cristóvão da Gama tiveram tão grandes êxitos.

[...] Entre os inúmeros episódios que mostram os invasores em inferioridade de armamento por continuarem no uso do antigo, está o que narra Duarte de Albuquerque em suas "Notas Diárias": "A 14 de maio de 1630, a escolta do Almirante Adrianzon, atacada de surpresa no istmo de Olinda pelo Capitão de Emboscadas João Mendes flores, não pôde fazer fogo por ter um aguaceiro inutilizado as mechas de suas armas. Nesse recontro, o Almirante perdeu até seu bastão de comando... As escopetas da [...] roda somente começaram a aparecer [...] assim mesmo com raridade entre os flamengos depois de 1634 (Barroso, 02/10/1948: 42 - grifos nossos).

Com essas palavras, Barroso reforça os laços identitários do Brasil com as origens lusitanas, e com outras, a continuidade do projeto de expansão da Igreja Católica nos trópicos: "O Brasil afirma de armas em punho, selando essa afirmação com muito sangue, seu desejo de permanecer fiel à sua tradição católica e à sua ancestralidade lusa" (Idem).

Nesses artigos, Gustavo Barroso apresenta aos leitores imagens de objetos que comprovam seu discurso. No caso do relato sobre a expulsão dos holandeses, expõe armas que atestam a superioridade bélica dos portugueses. São objetos que integram o acervo do $\mathrm{MHN}$, por ele dirigido. No corpo do texto, também 
há referência à "série de lindíssimas medalhas comemorativas das vitórias navais e terrestres dos flamengos existentes nas coleções do Museu Histórico" (Idem). O recurso à divulgação de imagens e à utilização de peças das coleções do Museu como ilustração dos artigos e, mais ainda, como documentação comprobatória das verdades reveladas por Barroso é muito comum nas páginas d'O Cruzeiro. A prática funciona não apenas como uma forma lúdica de atrair o leitor, uma vez que a "imagem é capaz de atingir todas as camadas sociais ao ultrapassar as diversas fronteiras sociais pelo alcance do sentido humano da visão" (Knauss, 2006: 99), mas também como uma maneira de convencer "seus destinatários de que o que ocorreu no passado aconteceu da forma como o enuncia" (Rüsen, 2010: 100), sustentando as pretensões de validade (Idem: 85) de seu discurso e fazendo com que seus leitores acreditem em suas revelações, interessando-se cada vez mais pelo passado.

Em outra direção, Barroso não perdia a oportunidade de divulgar o MHN, onde os "amigos da revista" O Cruzeiro poderiam ter contato direto com as relíquias do passado nacional, "verdadeiros testemunhos" da história narrada no semanário. Tal prática foi levada a cabo em sua escrita, mesmo após a supressão das imagens do espaço, até suas últimas colaborações, quando foi substituído por Pedro Calmon, que, ao assumir a coluna na revista, proferiu as palavras que abrem este artigo.

Notas

1. Ver http://www.memoriaviva.com.br/o cruzeiro/10111928/101128_4.htm (acesso em: 28/05/2014).

2. Em 1930, Gustavo Barroso decidiu apoiar a candidatura de Júlio Prestes em oposição à Aliança Liberal de Getúlio Vargas. Com o triunfo da Revolução de 1930, Vargas o afastou do comando do museu. Em novembro de 1932, foi reconduzido à direção do $\mathrm{MHN}$, onde permaneceu até sua morte.

3. Na visão de Gustavo Barroso, o Brasil era um país civilizado, digno de orgulho dos brasileiros, graças à ação colonizadora portuguesa, em especial por seu caráter cristão. O conceito de civilização expressa aqui, segundo Norbert Elias, "a consciência que o ocidente tem de si mesmo. Poderíamos até dizer a consciência nacional. Ele resume tudo em que a sociedade ocidental dos últimos dois ou três séculos se julga superior a sociedades mais antigas ou a sociedades contemporâneas 'mais primitivas" (Elias, 1994: 23).

4. Integrar a historia do Brasil à história da humanidade, recuando suas origens à Antiguidade, foi trabalho realizado por Varnhagen no século XIX, em suas buscas pela origem dos tupis. Conforme análise 


\section{Aline Montenegro Magalhães e Claudia Barroso Roquette-Pinto Bojunga}

de Temístocles Cezar, a obra do Visconde de Porto Seguro, L'Origine Touranienne des Américains Tupis-Caribes et des Anciens Egyptiens. Indiquée principalement par la philologie comparée: traces d'une ancienne migration en Amérique, invasion du Brésil par les Tupis, etc. procurou comprovar através de estudos filológicos e etnográficos que a origem dos Tupis remete aos antigos egípcios e aos cários, que teriam cruzado o Atlântico e invadido a terra. "Varnhagen teria deste modo comprovado que a ocupação tupi, efetuada em meio às maiores crueldades, [...] não foi mais do que uma invasão

Referências bibliográficas

ABREU, Alzira Alves de; BELOCH, Israel; LATTMAN-WELTMAN, Fernando; LAMARÃO, Sergio Tadeu de Niemeyer (coord.). Dicionário histórico-biográfico brasileiro pós-1930. Rio de Janeiro: Editora FGV/CPDOC, 2001.

BARBOSA, Marialva. O Cruzeiro: uma revista síntese de uma época da história da imprensa brasileira. Ciberlegenda, n. 7, 2000. Disponível em: http://www.uff.br/ ciberlegenda/ojs/index.php/revista/article/ view/331/212 (acesso em 30/06/2014).

BARROSO, Gustavo. A primeira imagem e a primeira cruz do Brasil. O Cruzeiro, 14/08/ 1948. In: GB60 V.1, Biblioteca do MHN.

O nome do Brasil mais antigo que o Brasil. O Cruzeiro, 28/08/1948. In: GB60 V.1, Biblioteca do MHN.

- A criação da Amazônia. O Cruzeiro, 18/09/1948. In: GB60 V.1, Biblioteca do MHN.

A primeira constituição e a primeira bandeira do Brasil. O Cruzeiro, cuja expiação teria chegado com Colombo e Cabral" (Cezar, 2005: 36). Neste caso o recuo no tempo foi feito no intuito de desvalorizar o passado em questão, o dos índios, o que é diferente da exaltação dos valores de civilização atribuídos aos povos da Antiguidade presente nos escritos barroseanos. Entretanto, não deixa de estar em jogo, em ambos os casos, a criação de um passado remoto para a história do Brasil, talvez no sentido de igualar sua história à das nações europeias.

25/09/1948. In: GB60 V.1, Biblioteca do MHN.

A cavalaria do sertão. $O$ Cruzeiro, 23/10/1948. In: GB60 V.1, Biblioteca do MHN.

A nossa guerra dos cem anos. $O$ Cruzeiro, 2/04/1949. In: GB60 V.1, Biblioteca do MHN.

Os ferros da escravidão. O Cruzeiro, 30/04/1949. In: GB60 V.1, Biblioteca do MHN.

Gobineau, o amigo de Pedro II. $O$ Cruzeiro, 28/05/1949. In: GB60 V.1, Biblioteca do MHN.

Um baiano na retirada da Rússia. O Cruzeiro, 28/05/1949. In: GB60 V.1, Biblioteca do MHN.

Os fenícios no Brasil. O Cruzeiro, 12/11/1949. In: GB60 V.1, Biblioteca do MHN.

Um Rei de Portugal, Imperador do Brasil. O Cruzeiro, 09/09/1950. In: GB60 V. 2, Biblioteca do MHN. 
O tacape de Tibiriçá. O Cruzeiro, 04?/08/1951. In: GB60 V. 2, Biblioteca do MHN.

D. João VI precursor da Abolição. O Cruzeiro, 11/09/1954. In: GB60 V. 4, Biblioteca do MHN.

BEZERRA, Rafael Zamorano. Valor histórico, exposição e restauração de objetos do acervo do Museu Histórico Nacional. Anais do Museu Histórico Nacional. Rio de Janeiro, v. 42, 2010.

CEZAR, Temístocles. A retórica da nacionalidade de Varnhagen e o mundo antigo: o caso da origem dos tupis. In: GUIMARÃES, Manoel Luiz Salgado (org.). Estudos sobre a escrita da história. Rio de Janeiro: 7 Letras, 2006, p. 29-41.

DE CETRTEAU, Michel. A escrita da história. Rio de Janeiro: Forense Universitária, 2000.

Editorial. O Cruzeiro. 10 de novembro de 1928. Disponível em http://www.memoria viva.com.br/ocruzeiro/10111928/101128_4 .htm (acesso em 31/08/2014).

ELIAS, Norbert. O processo civilizador: uma história dos costumes. Rio de Janeiro: Jorge Zahar, 1994.

FERREIRA, Marieta de Moraes. A História como ofício: a construção de um campo disciplinar. Rio de Janeiro: FGV, 2013.

GUIMARÃES, Manoel L. S. Historiografia e nação no Brasil: 1838-1857. Rio de Janeiro: EdUERJ, 2011.

HOBSBAWM, Eric \& RANGER, Terence. A invenção das tradições. Rio de Janeiro: Paz e Terra, 1997.

KNAUSS, Paulo. O desafio de fazer História com imagens: arte e cultura visual. $A r t$ Cultura. Uberlândia, v. 8 , n. 12, jan-jun, 2006.
KOSELLECK, Reinhart. Futuro passado. Contribuição à semântica dos tempos históricos. Rio de Janeiro: Contraponto/ Ed. PUC-Rio, 2006.

LIDDINGTON, Jill. O que é história pública? Os públicos e seus passados. In: ALMEIDA, Juniele Rabêlo de \& ROVAI, Marta Gouveia de Oliveira (org.). Introdução à história pública. São Paulo: Letra e Voz, 2011.

LUSTOSA, Isabel. Alma de colecionador: Plínio Doyle, entre amigos e livros. In: MAGALHÃES, Aline Montenegro \& BEZERRA, Rafael Zamorano. Coleções e colecionadores: a polissemia das práticas. Rio de Janeiro: Museu Histórico Nacional, 2012, p. 26-36.

MAGALHÃES, Aline Montenegro. Culto da saudade na Casa do Brasil - Gustavo Barroso e o Museu Histórico Nacional (19221959). Fortaleza: Museu do Ceará, Secretaria da Cultura do Estado do Ceará, 2006.

Gustavo Barroso e o colecionamento de si. In: — \& BEZERRA, Rafael Zamorano. Coleções e colecionadores: a polissemia das práticas. Rio de Janeiro: Museu Histórico Nacional, 2012, p. 60-68.

MEYRER, Marlise Regina. Natureza e identidade nacional nas páginas da revista O Cruzeiro na década de 50. Disponível em http://www.encontro2012.mg.anpuh.org/r esources/anais/24/1340650252_ARQUIVO NaturezaeidentidadadeAMPUHMG.pdf (acesso em 31/08/2014).

PEREGRINO, Nadja. O Cruzeiro: a revolução da fotorreportagem. Rio de Janeiro: Dazibao, 1991.

RÜSEN, Jörn. Razão histórica: teoria da história, fundamentos da ciência histórica. Brasília: Editora Universidade de Brasília, 2010. 


\section{Resumo}

Gustavo Barroso (1888-1959) colaborou na revista O Cruzeiro entre 1948 e 1960 assinando a seção "Segredos e revelações da História do Brasil", dedicada à divulgação de fatos da história pátria não abordados nos meios convencionais. Desejava atrair a atenção dos leitores para o passado de modo a estimular o patriotismo. O presente artigo analisa essa produção e a compreende como uma experiência de história pública, a partir da qual grandes feitos e heróis são exaltados sob a perspectiva das curiosidades desconhecidas do grande público. $\mathrm{O}$ trabalho aqui apresentado caracteriza essa narrativa e suas estratégias para atingir os objetivos pedagógicos da seção. Palavras-chave: Gustavo Barroso (1888-1959); escrita da história; história pública; revista $O$ Cruzeiro.

\section{Abstract}

Gustavo Barroso (1888-1959) contributed to the magazine O Cruzeiro between 1948 and 1960, signing the section "Secrets and revelations of the History of Brazil", dedicated to the dissemination of facts of national history unmentioned in conventional means of History diffusion. Barroso aimed to attract the readers' attention to the past as a way of stimulating the patriotism. This paper analyzes Gustavo Barroso's production for a wide audience, and characterizes his narrative and his strategies to achieve the pedagogical goal of the section in a magazine of great national circulation.

Keywords: Gustavo Barroso (1888-1959); history writing; public history; magazine $O$ Cruzeiro.

\section{Résumé}

Gustavo Barroso (1888-1959) a collaboré au magazine O Cruzeiro entre 1948 et 1960, signant la rubrique "Secrets et révélations de l'histoire du Brésil", dédiée à la divulgation des faits de l'histoire nationale ignorés par les méthodes conventionnelles de l'histoire. Son but était d'attirer l'attention des lecteurs sur le passé du pays afin d'encourager le patriotisme. Lobjectif de cet article est d'analyser la production de Gustavo Barroso en cherchant à caractériser les procédés narratifs et les stratégies qu'il utilise pour toucher ce vaste public et atteindre les desseins pédagogiques d'un périodique à grande diffusion.

Mots-clés: Gustavo Barroso (1888-1959); écriture de l'histoire; histoire publique; magazine $O$ Cruzeiro. 